Ildikó Szijj (D)

Universidade Eötvös Loránd de Budapeste

szijj.ildiko@btk.elte.hu

\title{
Observações sobre a derivação parassintética no português e no espanhol
}

\begin{abstract}
Resumo:
O meu objetivo é observar alguns aspetos dos derivados parassintéticos deadjetivais do português e do espanhol, formados com os prefixos $a$ - e en-. Este tipo de derivação existe em todas as línguas românicas, mas os elementos concretos podem divergir. Assim, pode aparecer um prefixo diferente no derivado, p. ex. port. encurtar / esp. acortar. Num par como port. apequenar / esp. empequeñecer vemos a diferença ao mesmo tempo no tipo de conjugação e no prefixo. Noutros casos, só uma das duas línguas tem um derivado parassintético, p. ex. esp. ensuciar / port. sujar. O derivado parassintético de uma das línguas pode ter como equivalente uma combinação de elementos lexicais, p. ex. esp. empequeñecer / port. tornar pequeno.
\end{abstract}

Palavras chave: derivação, parassíntese, português, espanhol, comparação morfológica

\section{Abstract:}

\section{Observations about Parasynthetic Derivation in Portuguese and Spanish}

My aim is to observe certain aspects of the deadjetival parasynthesis in Portuguese and Spanish, with the prefixes $a$ - and en-. This type of derivation exists in all romance languages, although concrete elements may diverge. A derived word may have a different prefix, ex. port. encurtar / sp. acortar. In port. apequenar / esp. empequeñecer the difference appears in the type of conjugation and in the prefix. In other cases only one of the languages has a parasynthetic derived word, ex. sp. 
ensuciar / port. sujar. The parasynthetic derived word may have a combination of lexical elements as an equivalent, ex. sp. empequeñecer / port. tornar pequeno. Keywords: derivation, parasynthesis, Portuguese, Spanish, morphological comparison

\section{Introdução}

A derivação parassintética existe em todas as línguas românicas: p. ex. port./esp. enriquecer, cat. enriquir, fr. enrichir, it. arricchire, rom. a îmbogăţi. No entanto, podemos ver na lista que os segmentos dos derivados não são iguais em todas as línguas, p. ex. a palavra portuguesa pertence à 2 a conjugação, enquanto a francesa tem a terminação -ir, isto é, a vogal temática é diferente. O derivado português tem o prefixo en-, ao passo que na palavra italiana aparece $a$-. Além disso, p. ex. a estrutura da forma catalã é en-riqu-ir, enquanto a forma portuguesa contém mais um segmento, -c-: en-riqu-ec-er. Por conseguinte, embora o fenómeno da parassíntese seja comum, entre as línguas há diferenças que merecem ser examinadas com maior atenção.

Antes de mais, é preciso dizer que nem todos os linguistas concordam no uso do termo parassintético. A categoria pode referir-se a diferentes conceitos, de acordo com o fundo teórico. Segundo uma das aproximações, elementos como cat. en-riqu-ir são derivados parassintéticos, porque têm um prefixo e um sufixo, sendo p. ex. esta a interpretação de Reinheimer-Rîpeanu (1974), que estudou a questão em diferentes línguas românicas, de Serrano Dolader (1999: 46834755), no caso do espanhol, de Bruguera (2006: 20), para o catalão, de Cunha e Cintra (1984: 103) ou Câmara (1985: 226), para o português. O DLPC, na definição do termo parassintético, dá como exemplo o verbo enterrar (derivado denominal), adotando portanto o mesmo ponto de vista.

Segundo a outra aproximação, entre os exemplos anteriores o único derivado parassintético da lista seria a forma portuguesa e espanhola en-riqu-ec-er, que contém o sufixo -ec-além do morfema verbal -er. Esta é p. ex. a interpretação de Cabré (2002: 741), para o catalão. Para 
outras teorias, v. Rainer (2016: 517). Irei aplicar o termo no primeiro sentido, mais amplo, isto é, vou considerar também derivados parassintéticos, casos como fr. enrichir ou port. alargar.

O meu objetivo é observar os derivados verbais deadjetivais formados com os prefixos $a$ - e en- no português e no espanhol. Escolhi estes dois prefixos, porque se podem comparar facilmente, já que têm basicamente a mesma função, como se pode comprovar nas seguintes derivações: baixo - abaixar 'tornar baixo', curto - encurtar 'tornar curto'. Vejamos alguns exemplos que mostram que, para bases semanticamente parecidas, o derivado nem sempre tem o mesmo prefixo. P. ex. se a base expressar medida, podemos ter alargar, encurtar; com um adjetivo que significa cor, acastanhar, empardecer; uma deficiência, adoidar, ensurdecer; um estado mental, amalucar, endoidecer; um estado de ânimo, aquietar, entristecer; um grau de consistência, afofar, endurecer.

A derivação verbal deadjetival pode produzir-se por parassíntese, mas também sem prefixo, p. ex. cegar, contentar, sujar, limpar, tranquilizar. Segundo Villalva (2003: 953), os prefixos $a$ - ou en- nos parassintéticos "têm uma mera função fática, de reforço expressivo" e podem caracterizar-se como elementos "expletivos" (Villalva 2008: 134), já que noutros elementos léxicos a derivação verbal se produz sem prefixo.

Também há casos quando não há um verbo correspondente ao adjetivo, p. ex. feliz, preto, simpático.

$\mathrm{O}$ verbo correspondente ao adjetivo pode vir do latim, sendo que neste caso o derivado não tem uma estrutura claramente segmentável, porque a base do derivado sofre uma modificação, p. ex. cheio - encher (lat. IMPLERE), dificil-dificultar (lat. tardio DIFFICULTARE).

Tendo em conta que os prefixos $a$ - e $e n$ - têm a mesma função nos derivados parassintéticos deadjetivais, e que a derivação verbal deadjetival se pode produzir também sem prefixo, se compararmos duas línguas, podemos pensar que encontraremos diferenças entre elas. O meu objetivo principal será, portanto, ver em que medida divergem o português e o espanhol na forma dos parassintéticos deadjetivais formados com os prefixos $a$ - e en-. 


\section{Derivados parassintéticos nas línguas românicas}

Antes de mais, vou comparar muito brevemente, do ponto de vista da forma, os derivados parassintéticos deadjetivais nas diferentes línguas românicas. Existem as seguintes possibilidades de combinação de prefixo e desinência verbal: port. aclarar, amadurecer, engordar, envelhecer; esp. aclarar, ablandecer, entibiar, enaltecer; cat. abaixar, abaratir, emborratxar, emblanquir; fr. accommoder, affaiblir, enivrer, enlaidir; it. abbassare, abbellire, ingrassare, ingrandire; rom. asigura, amuţi, îmbuna, îmbogăţi. Como se observa a partir dos exemplos, o português e o espanhol diferenciam-se das outras línguas, porque não formam verbos acabados em -ir, mas sim em -ecer. Por conseguinte, do ponto de vista morfológico, estas duas línguas apresentam uma semelhança dentro do grupo românico. É por este motivo que comparo estas duas línguas.

\section{Português}

No DLCP aparecem os seguintes parassintéticos deadjetivais:

Combinação a-ar: abastardar, abonar, abrandar, abrasileirar, abrejeirar, abrilhantar, abrutalhar, aburguesar, acalmar, acastanhar, acastelhanar, acertar, achatar, achinesar, aciganar, aclarar, acobardar, acomodar, adelgadar, adestrar, adoçar, adocicar, adoidar, afear, afinar, afixar, afofar, aformosear, aforrar, afrancesar, afundar, agalegar, agigantar, agravar, ajustar, alambazar-se, alargar, alatinar, aligeirar, alimpar, alindar, alisar, alongar, alourar, amaciar, amadurar, amalucar, amarotar-se, amarrecar, ameigar, amesquinhar, amimalhar, amiudar, amochar, amodernar, amofinar, amolar, amolengar, amorenar, amornar, amouriscar, amulatar, apalermar, aparvalhar, aparvoar, apassivar, apatetar, apequenar, aplanar, aportuguesar, aprofundar, aprontar, aproximar, apurar, aquietar, arrasar, arredondar, arroxar, arroxear, assegurar, atenuar, avelhentar, avermelhar, aviventar (84)

Combinação a-ecer: amadurecer, apodrecer (2) 
Combinação en-ar: emaciar, emborrachar, emburguesar, emporcalhar, encalmar, encrespar, encurtar, endireitar, endoidar, enfartar, enfear, engordar, engravidar, engrossar, enloirar, enricar, enrijar, ensoberbar, entortar, enviuvar (20)

Combinação en-ecer: emagrecer, embrandecer, embranquecer, embravecer, embrutecer, empalidecer, empardecer, empobrecer, етиdecer, emurchecer, enaltecer, encalvecer, encarecer, endoidecer, endurecer, enegrecer, enfraquecer, engrandecer, enloirecer, enlouquecer, enobrecer, enrijecer, enriquecer, enrouquecer, ensoberbecer, ensurdecer, enternecer, entontecer, entorpecer, entristecer, envelhecer, enverdecer, envermelhecer, envilecer (34)

Incluí na lista os elementos que, segundo o DLPC, têm uma origem composicional, p. ex. empobrecer: em+pobre+ecer. Por outro lado, também tive em conta palavras que vêm diretamente do latim, mas segundo o critério sincrónico também podem ser considerados como derivados: aclarar $<$ ACCLARARE, alongar $<*$ ALLONGARE (etimologias do DLPC). O falante atual pode interpretar a estrutura das palavras como $a+c l a r o+a r, a+$ longo $+a r$. Outras palavras semelhantes são: acomodar, agravar, apodrecer, aproximar, atenuar, emaciar, emagrecer, entorpecer.

No caso das palavras amolengar e apalermar não é evidente se a base (molenga, palerma) é um adjetivo ou um substantivo. Podemos ter a mesma dúvida no caso dos derivados formados a partir de gentílicos (aportuguesar, abrasileirar, etc.).

Há ainda na lista outras palavras que, tendo em conta as indicações do dicionário, supõem certos problemas etimológicos. Assim, amarrecar segundo o DLPC tem a estrutura $a+$ marreca $+a r$. Nesse sentido seria um derivado denominal. Mas a etimologia também poderia ser $a+$ marreco $+a r$, sendo que neste caso seria um derivado deadjetival. Para acalmar e encalmar o dicionário indica a estrutura $a /$ en+calma $+a r$, mas se supomos que a etimologia é a/en+calmo+ar, trata-se de uma derivação deadjetival. A justificação da minha proposta 
é que não parece normal que na derivação parassintética denominal a base seja um substantivo abstrato. Incluí estas palavras na lista. (O dicionário Houaiss indica duas etimologias diferentes para as duas variantes: $a+$ calma $+a r$, mas en+calmar.) Podemos comparar a palavra com ensoberbar, para a qual o dicionário indica a estrutura en+soberbo +ar. (No entanto, também devemos ter em conta o parassintético embelezar, derivado do substantivo beleza, segundo o DLPC e segundo o dicionário Houaiss. Seria difícil afirmar que a base é belo, já que não existe o sufixo -ezar.) Outra palavra cuja etimologia no DLPC pode ser discutível é alimpar. O dicionário indica a derivação $a+$ limpar, aqui também podemos questionar se não seria possível $a+$ limpo $+a r$, que é a etimologia indicada pelo dicionário Houaiss. Incluí todas estas palavras na lista.

No caso normal, a estrutura das palavras parassintéticas é a/ en+adjetivo+ar/ecer. No entanto, certas palavras têm mais um segmento: abrutalhar (a+bruto+alho+ar), emporcalhar, aparvalhar $($ em + porcalhão $+a r, a+$ parvalhão $+a r$, etimologias indicadas no DLCP). Como se pode comprovar, o dicionário nem sempre é coerente, porque indica as etimologias de duas formas discrepantes. Também aparece mais um segmento no verbo adocicar. Noutros casos aparece um sufixo diferente de -ar ou -ecer, nomeadamente -ear: aformosear, arroxear. Os verbos avelhentar, aviventar têm a estrutura $a+v e l h o+e n t a r, a+v i v o+e n t a r$, segundo o dicionário. Outra palavra de estrutura irregular é aparvoar, para o qual o dicionário indica a etimologia $a+$ parvo $+a r$. No plano sincrónico é pouco claro porque se conserva o índice temático da base; a origem da palavra é que explica a presença da vogal: PARVULUM > parvoo > parvo; aparvoar nasceu da base parvoo, quando o primeiro $o$ fazia parte do radical. (Na família de palavras de parvo esta vogal $o$ aparece também noutros elementos: parvoeira, parvoeirar, parvoejar, parvoice, parvoinho).

Os derivados podem ter variantes. Segundo o DLPC pode existir o derivado parassintético e paralelamente o verbo sem prefixo nos seguintes casos: formosear / aformosear, madurar / amadurar / amadurecer, calmar / acalmar / encalmar, branquear / branquejar / embranquecer. Pode haver variantes com os dois prefixos: afear / 
enfear, acalmar / encalmar, aburguesar / emburguesar, avermelhar / envermelhecer, adoidar / endoidar. Pode variar o sufixo: amadurar / amadurecer, enrijar / enrijecer, endoidar / endoidecer, enricar / enriquecer, enloirar / enloirecer, ensoberbar / ensoberbecer, avermelhar / envermelhecer, aparvalhar / aparvoar.

O prefixo que aparece em quase todos os casos com o sufixo -ecer é en-, p. ex. empobrecer.

A ordem de frequência entre as quatro estruturas é a seguinte: $a$ - $a r$, en-ecer, en-ar, a-ecer.

\section{Espanhol}

Para o espanhol usei, em primeiro lugar, o dicionário Clave (2012) e também o DRAE (2018), para comprovar a existência das palavras. Para comparar os derivados portugueses com os espanhóis tive em conta os elementos formados a partir de bases lexicalmente parecidas nas duas línguas.

Vejamos as diferenças por ordem alfabética: P abastardar - E no dicionário Clave não aparece nenhum derivado, segundo o DRAE bastardar ou bastardear; P acastelhanar - E castellanizar; P adoçar - E endulzar, segundo o DRAE também adulzar, pouco usado; P aformosear (também formosear) - E hermosear; P agalegar - E galleguizar; P alatinar - E latinizar; P amadurar / madurar / amadurecer - E madurar; P amesquinhar - E mezquinar (DRAE); P amodernar - E modernizar; P apequenar - E empequeñecer; P apodrecer - E pudrir; $\mathrm{P}$ aprofundar - E profundar / profundizar; E apurar - $\mathrm{P}$ purificar; $\mathrm{P}$ arredondar - E redondear, segundo o DRAE também arredondear; P arroxar - E enrojecer; P arroxear - E rojear; P emburguesar (também aburguesar) - E aburguesar; P empalidecer - E empalidecer / palidecer; P encurtar - E acortar; P enfartar - E hartar; P enfear (também afear) - E afear; P enverdecer - E verdecer / verdear, segundo o DRAE também enverdecer.

Vejamos as diferenças também na direção contrária, tendo como ponto de partida o dicionário Clave. Esta comparação é necessária para 
verificar se no espanhol há derivados com prefixo que não existem ou são diferentes em português. Derivados discrepantes: E abaratar / baratear - P baratar, baratear; E empeorar - P piorar; E enajenar $\mathrm{P}$ alhear; E enceguecer / cegar - P cegar; E ensuciar - P sujar.

Nem sempre é fácil comparar as duas línguas, porque em certos casos há diferentes variantes e não só uma equivalência biunívoca entre as línguas. Uma diferença que se observa em vários casos é que, em português, com adjetivos que indicam procedência aparece o prefixo en-, sendo que em espanhol o derivado não tem prefixo e a terminação é -izar: P acastelhanar - E castellanizar, P agalegar - E galleguizar, $\mathrm{P}$ alatinar - E latinizar. Outros pares com a mesma diferença são P amodernar - E modernizar, P aprofundar - E profundizar. Além destes casos há outros em que o português tem o prefixo $a$-, ao passo que o espanhol tem en- ou não tem prefixo (abastardar - bastardar, adoçar-endulzar, aformosear-hermosear, amadurar-madurar, amesquinhar - mezquinar, apasivar-pasivar, apequenar - empequeñecer, apodrecer-pudrir, aprofundar-profundar, apurar-purificar, arroxear - rojear). São menos numerosos os casos em que o português tem en- e o espanhol $a$ - ou não tem prefixo (emburguesar - aburguesar, empalidecer - palidecer, encurtar - acortar, enfartar - hartar, enfear-afear). Partindo do espanhol, há só algumas diferenças, em primeiro lugar quando o derivado espanhol tem o prefixo en-, enquanto o português não tem prefixo.

Entre as duas línguas a diferença aparece com maior frequência no prefixo, sendo que a terminação discrepa muito poucas vezes: $\mathrm{P}$ apequenar - E empequeñecer, $\mathrm{P}$ arroxar - E enrojecer, nos dois casos há também uma diferença no prefixo. Também há diferenças na terminação por uma das línguas ter um sufixo diferente, sendo da mesma conjugação: P acastelhanar - castellanizar (e outros exemplos parecidos já mencionados), bastardar-bastardear, apurar-purificar, arredondar - redondear.

Em resumo, na maior parte das vezes encontramos o mesmo derivado nas duas línguas. Nos casos em que o derivado já existia no latim ou no latim vulgar, esta semelhança é evidente, nos outros casos, porém, chama a atenção, porque os derivados se formaram na fase 
românica, quando as duas línguas já tinham tomado rumos diferentes. Os derivados iguais são os seguintes:

Combinação $a$-ar:

P abonar, abrandar (ablandar), abrilhantar (abrillantar), aburguesar, acastanhar (acastañado como adjetivo), acertar, achatar, achinesar (achinar), aciganar (corresponde a agitanar), aclarar, acobardar, acomodar, adoçar (adulzar, pouco usado), afear, afinar, afixar (afijar), afrancesar, afundar (ahondar), agigantar, agravar, ajustar, alargar, aligeirar (aligerar), alimpar (alimpiar, desusado, mas aparece no DRAE), alisar, amouriscar (amoriscado), amulatar (amulatado), aplanar, aproximar, aquietar, arrasar, assegurar (asegurar), atenuar, avelhentar (avejentado) 34

$\mathrm{Na}$ lista ponho entre parênteses a palavra espanhola quando a forma gráfica é diferente da portuguesa. Nalguns casos, no espanhol, no dicionário só aparece o particípio, e não o infinitivo, mas também tenho em conta estes casos como coincidências. No dicionário português havia 84 parassintéticos com combinação $a$-ar, 33 dos quais não podem ser comparados com o espanhol, porque a base é um elemento léxico inexistente nesta língua. Dos 51 com equivalente léxico, 34, isto é, 66\% são iguais nas duas línguas. Entre os derivados iguais 5 podem ser explicados por terem uma etimologia comum no latim vulgar: ACCLARARE, ACCOMODARE, AGGRAVARE, APPROXIMARE, ATTENUARE. Tirando estes elementos, a coincidência entre as duas línguas é de $63 \%$.

Combinação en-ar:

emborrachar, encalmar, encrespar, engordar, engrossar (engrosar), entortar, enviuvar (enviudar) 7

Dos 20 derivados do português 6 não podem ser comparados, porque no espanhol não existe a mesma base como elemento léxico. Dos 14 casos 7 coincidem nas duas línguas, isto é, 50\%. Nenhum dos 
verbos iguais vem do latim vulgar, mas formaram-se já nas línguas românicas.

Combinação en-ecer:

embrandecer (emblandecer), embranquecer (emblanquecer), embravecer, embrutecer, empalidecer, empobrecer, emudecer (enmudecer), enaltecer, encalvecer, encarecer, endurecer, enegrecer (ennegrecer), enfraquecer (enflaquecer), engrandecer, enlouquecer (enloquecer), enobrecer (ennoblecer), enriquecer, enrouquecer (enronquecer), ensurdecer (ensordecer), enternecer, entontecer, entorpecer, entristecer, envelhecer (envejecer), enverdecer, envilecer 26

Dos 34 casos do português 6 não se podem comparar. Dos 28 casos restantes 26 coincidem, isto é, $92 \%$ dos elementos. Nenhum dos verbos iguais vem do latim vulgar, tendo nascido na fase românica.

\section{Conclusão}

Se compararmos o fenómeno da derivação parassintética entre as cinco principais línguas românicas, comprovamos que o português e o espanhol coincidem no facto de formarem verbos acabados em -ecer, enquanto nas outras línguas nascem verbos acabados em -ir/-ire/-i. Mas não é esta a única semelhança entre as duas línguas. Se observarmos a lista dos derivados parassintéticos adjetivais formados com os prefixos $a$ - e en- (excluindo as palavras em que a base lexical não é igual nas duas línguas e os casos em que o elemento veio como palavra derivada já do latim vulgar), constatamos que a coincidência é considerável, em primeiro lugar no caso dos que têm a estrutura en-ecer. Observam-se mais diferenças entre os prefixos do que entre os tipos de conjugação.

\section{Referências bibliográficas}

BRUGUERA, J. (2006), Diccionari de la formació de mots, Enciclopèdia Catalana, Barcelona.

CABRÉ, M.T. (2002), "La derivació" em: Solà, J. [et al.], Gramàtica del català contemporani, Empúries, Barcelona, 1, pp. 731-775. 
CÂMARA Jr., MATTOSO, J. (1985), História e Estrutura da Língua Portuguesa, Padrão, Rio de Janeiro.

Clave, Diccionario de uso del español actual (2012), 9 ed., SM, Madrid.

CUNHA, C. FERREIRA DA, CINTRA, L.L. (1984), Nova Gramática do Português Contemporâneo, Sá da Costa, Lisboa.

Diccionario de la Real Academia Española (2014), 23 ed., actualização de 2018, Real Academia Española, [on-line] https://dle.rae.es - 26.09.2019.

Dicionário da Língua Portuguesa Contemporânea (2001), Academia das Ciências de Lisboa, Verbo, Lisboa, https://doi.org/10.5628/rpcd.01.03.03.

Dicionário Houaiss da língua portuguesa (2009), Instituto Antônio Houaiss de Lexocografia, Objetiva, Rio de Janeiro.

RAINER, F. (2016), "Derivational morphology” em: Ledgeway, A., Maiden, M. (eds.), The Oxford Guide to the Romance Languages, Oxford University Press, Oxford, pp. 513-523, https://doi.org/10.1093/acprof:o so/9780199677108.003.0028.

REINHEIMER-RÎPEANU, S. (1974), Les dérivés parasynthétiques dans les langues romanes, Mouton, The Hague, Paris, https://doi. org/10.1515/9783111356785.

SERRANO DOLADER, D. (1999), "La derivación verbal y la parasíntesis", em: Bosque, I., Demonte, V. (eds.), Gramática descriptiva de la lengua española, Espasa, Madrid, pp. 4683-4755.

VILLALVA, A. (2003), "Formação de palavras, afixação" em: Mateus, M. H. M. [et al.] (eds.), Gramática da Lingua Portuguesa, 5 ed., revista e aumentada, Caminho, Lisboa, pp. 939-967.

VILlALVA, A. (2008), Morfologia do Português, Universidade Aberta, Lisboa. 